\title{
Bone Marrow Involvement
}

National Cancer Institute

\section{Source}

National Cancer Institute. Bone Marrow Involvement. NCI Thesaurus. Code C8288.

Infiltration of the bone marrow by a malignant neoplasm. 